\title{
Two new botcinin derivatives encountered in the studies of secondary metabolites from the marine-derived fungus Botryotinia sp. SF-5275
}

\author{
Min-Young Kim ${ }^{1}$, Jae Hak Sohn ${ }^{1}$, Jae-Hyuk Jang ${ }^{2}$, Jong Seog $\mathrm{Ahn}^{2}$ and Hyuncheol $\mathrm{Oh}^{1}$ \\ The Journal of Antibiotics (2012) 65, 161-164; doi:10.1038/ja.2011.133; published online 18 January 2012
}

Keywords: bioactive secondary metabolites; botcinins; botryotinia sp.; marine-derived fungus

Marine microorganisms are recognized as an important source of structurally diverse bioactive secondary metabolites. ${ }^{1,2}$ Studies of marine fungi as potential sources of new bioactive compounds have been relatively limited to date, but such studies have led to the discovery of new natural products, including many with novel carbon skeletons, providing compelling evidence that marine-derived fungi have the potential to be a rich source of pharmaceutical leads. ${ }^{3,4}$

The insulin-antagonizing activity of protein tyrosine phosphatase $1 \mathrm{~B}$ (PTP1B) is a factor in the negative regulation of the insulin pathway and a promising target for treatment of diabetes and obesity. Anchored to the endoplasmic reticulum, PTP1B is involved in the insulin receptor dephosphorylation process, negatively regulating insulin pathway signaling. ${ }^{5,6}$ Several studies indicate that PTP1B is also implicated in the inhibition of leptin signaling, which inhibits food intake and promote energy expenditure. ${ }^{7}$

As a part of our ongoing studies on PTP1B inhibitory secondary metabolites from marine microorganisms from Korea, we have investigated the chemical constituents of an extract obtained from cultures of the marine-derived fungus Botryotinia sp. SF-5275, of which the organic extract displayed PTP1B inhibitory effect $(60 \%$ inhibition at the $30 \mu \mathrm{g} \mathrm{ml}^{-1}$ level). This paper describes the isolation, structure elucidation and biological activity of the metabolites encountered in this investigation.

Botryotinia sp. SF-5275 (deposited at the College of Medical and Life Sciences fungal strain repository, Silla University) was isolated from an unidentified marine algae sample collected from Seongsan Port area at Cheju, Korea in February, 2009. The sample was diluted 10 -fold using sterile seawater. One milliliter of the diluted sample was processed utilizing the spread plate method using a medium consisting of $24 \mathrm{~g}$ of potato dextrose broth (Difco, Sparks, MD, USA) and $20 \mathrm{~g}$ of agar (Bio Basics, Inc., Ontario, Canada) in 11 of $75 \%$ filtered natural seawater. The plate was incubated at $25^{\circ} \mathrm{C}$ for 14 days. The fungal culture SF-5275 was identified based on analysis of the ribosomal RNA (rRNA) sequences. A GenBank search with the 28S rRNA gene of SF5275 (Genbank accession number HQ602686) indicated Botryotinia fuckeliana (AY544651) as the closest match showing sequence identity of $99 \%$. Therefore, the marine-derived fungal strain SF-5275 was characterized as Botryotinia sp.

The fungal strain was cultured on 27 petri plates $(90 \mathrm{~mm})$, each containing $20 \mathrm{ml}$ of potato dextrose agar medium $(2.4 \%$ (w/v) potato dextrose broth, $2.0 \%(\mathrm{w} / \mathrm{v})$ agar) prepared with $75 \%$ seawater. Plate cultures were incubated at $25^{\circ} \mathrm{C}$ for 14 days. Extraction of the agar media with MEK (11) provided an organic phase, which was then concentrated in vacuo to yield $633 \mathrm{mg}$ of an extract. This MEK extract was subjected to $C_{18}$ flash column chromatography $(5 \times 40 \mathrm{~cm}$, YMC ODS-A, S-75 $\mu \mathrm{m}$, YMC Co., Ltd., Kyoto, Japan), eluting with a stepwise gradient of $20,40,60,80$ and $100 \%(\mathrm{v} / \mathrm{v}) \mathrm{MeOH}$ in $\mathrm{H}_{2} \mathrm{O}$ $(500 \mathrm{ml}$ each). The fractions eluted at $80 \%(84.4 \mathrm{mg})$ and $100 \%$ $\mathrm{MeOH}(69.8 \mathrm{mg})$ were combined and purified by semi-preparative reversed-phase HPLC (Agilent prep- $\mathrm{C}_{18}$ column $(21.2 \times 150 \mathrm{~mm} ; 5 \mu \mathrm{m}$ particle size, Agilent Technologies, Santa Clara, CA, USA); flow rate of $5 \mathrm{ml} / \mathrm{min}$; detection at $210 \mathrm{~nm}$ ) eluting with a gradient from $70 \%$ to $90 \% \mathrm{MeOH}$ in $\mathrm{H}_{2} \mathrm{O}(0.1 \%$ formic acid $)$ over $60 \mathrm{~min}$, then $100 \%$ $\mathrm{MeOH}$ for $20 \mathrm{~min}$, to yield $\mathbf{1 a}\left(4.8 \mathrm{mg}, t_{\mathrm{R}}=18.0 \mathrm{~min}\right), \mathbf{1}(16.2 \mathrm{mg}$, $\left.t_{\mathrm{R}}=19.0 \mathrm{~min}\right)$ and $2\left(11 \mathrm{mg}, t_{\mathrm{R}}=32.0 \mathrm{~min}\right)$. The structures of previously known 1, 1a and 2 (Figure 1) were elucidated by analysis of NMR and MS data, together with comparison of their spectral data with those in the literature. ${ }^{8-10}$

In the course of biological and chemical studies of these compounds, the instability of botcinin A (1) in methanol solution was

${ }^{1}$ College of Medical and Life Sciences, Silla University, Busan, Korea and ${ }^{2}$ Chemical Biology Research Center, Korea Research Institute of Bioscience and Biotechnology (KRIBB), Chungbuk, Korea

Correspondence: Professor H Oh, College of Medical and Life Sciences, Silla University, Busan 617-736, Korea.

E-mail: hoh@silla.ac.kr

Received 20 September 2011; revised 5 December 2011; accepted 7 December 2011; published online 18 January 2012 
<smiles>[R7][C@H](O)/C=C/C(=O)O[C@@H]1[C@H](C)[C@@H]2OC(=O)[C@H](C)[C@H](OC(C)=O)[C@@]2(C)O[C@@H]1C</smiles>

botcinin $\mathrm{A}\left(\mathbf{1} ; \mathrm{R}^{1}={ }^{n} \mathrm{Bu}\right)$

botcinin $B\left(2 ; R^{1}={ }^{n} \mathrm{Hex}\right)$<smiles>[R7][C@H](O)/C=C/[Z](=O)O[C]1[C@@H](C)O[C@](C)([C@H](OC(C)=O)[C@@H](C)C(=O)OC)[C@H](O)[C@@H]1C</smiles>

3-O-acetylbotcinic acid methyl ester $\left(\mathbf{1} \mathbf{a} ; \mathrm{R}^{1}={ }^{n} \mathrm{Bu}\right)$

3-O-acetylbotcineric acid methyl ester $\left(2 \mathrm{a} ; \mathrm{R}^{1}={ }^{n} \mathrm{Hex}\right)$<smiles>[R][C@H](O)/C=C/C(=O)O[C@@H]1[C@H](C)[C@@H]2OC(=O)C(C)=C[C@@]2(C)O[C@@H]1C</smiles>

$$
\text { botcinin } D\left(\mathbf{1 b} ; R^{1}={ }^{n} \mathrm{Bu}\right)
$$$$
\text { botcinin } \mathrm{G}\left(\mathbf{2} \mathbf{b} ; \mathbf{R}^{1}={ }^{n} \mathrm{Hex}\right)
$$

Figure 1 Structures of Compounds 1-2b.

recognized, and the transformation of compound 1 was monitored in methanol over several days at room temperature by HPLC analysis (Supplementary Information). In this analysis, compound $\mathbf{1}$ was shown to be slowly converted to previously known 3-O-acetylbotcinic acid methyl ester (1a) and botcinin D (1b), which were identified upon isolation and subsequent structural analysis. This observation indicated that the hexahydropyrano[3,2,b]pyran-2(3H)-one moiety in botcinin A (1) is particularly unstable in methanol, and undergoes both slow methanolysis and elimination of acetic acid under mild conditions. Analogs behavior was also observed for botcinin B (2), leading to the isolation and identification of additional new compounds designated 3-O-acetylbotcineric acid methyl ester (2a, Figure 1) and botcinin $\mathrm{G}$ (2b, Figure 1).

The molecular formula $\mathrm{C}_{25} \mathrm{H}_{42} \mathrm{O}_{9}$ for $\mathbf{2 a}$ (Table 1) was suggested on the basis of NMR and HRESIMS data. The ${ }^{13} \mathrm{C}$ NMR and DEPT spectra of 2a were almost identical with those of 3-O-acetylbotcinic acid methyl ester (1a) except for the presence of signals corresponding to two additional methylene carbons $\left(\delta_{C} 29.0 \sim 31.7\right)$. This observation, together with the observed difference in mass, suggested that compound 2a possesses an alkyl chain with two additional methylene units as compared with that of compound 1a. Further interpretation of COSY, HSQC and HMBC NMR data for 2a (Table 2) allowed assignment of all ${ }^{1} \mathrm{H}$ and ${ }^{13} \mathrm{C}$ NMR resonances, and confirmed the
Table 1 Physicochemical properties of compounds $2 \mathrm{a}$ and $2 \mathrm{~b}$

\begin{tabular}{lcc}
\hline & $\mathbf{2 a}$ & $\mathbf{2 b}$ \\
\hline Appearance & Colorless gum & Colorless gum \\
{$[\alpha]_{D}^{25}$} & $+50(c 1.0, \mathrm{EtOH})$ & $+12(c 2.5, \mathrm{EtOH})$ \\
Molecular formula & $\mathrm{C}_{25} \mathrm{H}_{42} \mathrm{O}_{9}$ & $\mathrm{C}_{22} \mathrm{H}_{34} \mathrm{O}_{6}$ \\
& & \\
HR-ESI-MS $(\mathrm{m} / z)$ & & \\
Found & $487.2883[\mathrm{M}+\mathrm{H}]^{+}$ & $395.2446[\mathrm{M}+\mathrm{H}]^{+}$ \\
Calcd & 487.2907 & 395.2434 \\
UV (EtOH) $\lambda_{\max }(\log \varepsilon) \mathrm{nm}$ & $209(4.00)$ & $208(4.16)$ \\
\hline
\end{tabular}

proposed structure. Analysis of coupling constants and comparisons with corresponding values in compound 1a indicated that $2 \mathbf{a}$ has the same relative configuration as that of 3-O-acetylbotcinic acid methyl ester (1a).

The molecular formula $\mathrm{C}_{22} \mathrm{H}_{34} \mathrm{O}_{6}$ for compound $\mathbf{2 b}$ (Table 1) was suggested on the basis of NMR and HRESIMS data. The ${ }^{13} \mathrm{C}$ NMR and DEPT were very similar to those of botcinin D (1b) except for the presence of signals corresponding to two additional methylene units. This observation, together with the observed difference in mass, suggested that compound $\mathbf{2} \mathbf{b}$ possesses an alkyl chain with two additional methylene units as compared with that of compound 1b. Further interpretation of COSY, HSQC and HMBC NMR data (Table 2) of $\mathbf{2 b}$ allowed assignment of all ${ }^{1} \mathrm{H}$ and ${ }^{13} \mathrm{C}$ NMR resonances, and confirmed the suggested structure. The stereochemistry of compound $\mathbf{2} \mathbf{b}$ was suggested to be analogous to that of $\mathbf{1 b}$ on the basis of close similarities in relevant chemical shifts and $J$-values. As compounds $\mathbf{2 a}$ and $\mathbf{2} \mathbf{b}$ were derived from botcinin B (2), the absolute configurations of $\mathbf{2 a}$ and $\mathbf{2 b}$ were suggested to be analogous to that of $2 .{ }^{8}$

The PTP1B inhibitory activities of the isolated compounds were evaluated in vitro, and, among the tested compounds, botcinin B (2) exhibited the strongest inhibitory activity in a dose-dependent manner, with an $\mathrm{IC}_{50}$ value of $53.6 \mu \mathrm{M}$. The $\mathrm{IC}_{50}$ value of compound 2b $(96.2 \mu \mathrm{M})$ was $\sim$ twofold lower than that of $\mathbf{2}$. On the other hand, compounds $\mathbf{1}$ and $\mathbf{1 b}$ displayed much lower inhibitory effects, with $\mathrm{IC}_{50}$ values of $340.7 \mu \mathrm{M}$ and $461.2 \mu \mathrm{M}$, respectively, and compounds 1a and 2a did not show any inhibitory activity up to the $616.9 \mu \mathrm{m}$ level. A known phosphatase inhibitor, ursolic acid $\left(\mathrm{IC}_{50}=3.1 \mu \mathrm{M}\right)$, was used as a positive control in the assay. ${ }^{11}$ Although the magnitude of inhibitory activity of these compounds against PTP1B was modest, a structure-activity relationship was conferred upon examination of the structures and their corresponding activities. First, the length of the acyl chain appears to be important, because botcinin A (1) is less active than boticin B (2), whose acyl chain is longer than that of $\mathbf{1}$. A similar pattern was observed for compounds $\mathbf{1 b}$ and $\mathbf{2} \mathbf{b}$. In addition, the presence of the hexahydropyrano[3,2,b]pyran-2(3H)-one moiety was suggested to be an important structural feature for the inhibitory effect on PTP1B, because a loss (1 vs $\mathbf{1 b}$ and $\mathbf{2}$ vs $\mathbf{2 b}$ ) or disappearance (1 vs $\mathbf{1 a}$ and $\mathbf{2}$ vs $\mathbf{2 a}$ ) of inhibitory activity was observed with the degradation of this ring system in the respective compounds.

Next, the kinetics of PTP1B inhibition by 2 were explored, using different concentrations of a substrate in an effort to elucidate the mode of inhibition. When $p$-nitrophenyl phosphate ( $p$ NPP) was used as a substrate, compound 2 decreased the $V_{\max }$ value, but did not alter the $K_{m}$ value of PTP1B (Figure 2). Therefore, it was shown that botcinin B (2) behaves as non-competitive inhibitors of PTP1B, 
Table 2 NMR Data for 3-0-acetylbotcineric acid methyl ester (2a) and botcinin G (2b) in $\mathrm{CDCl}_{3}$

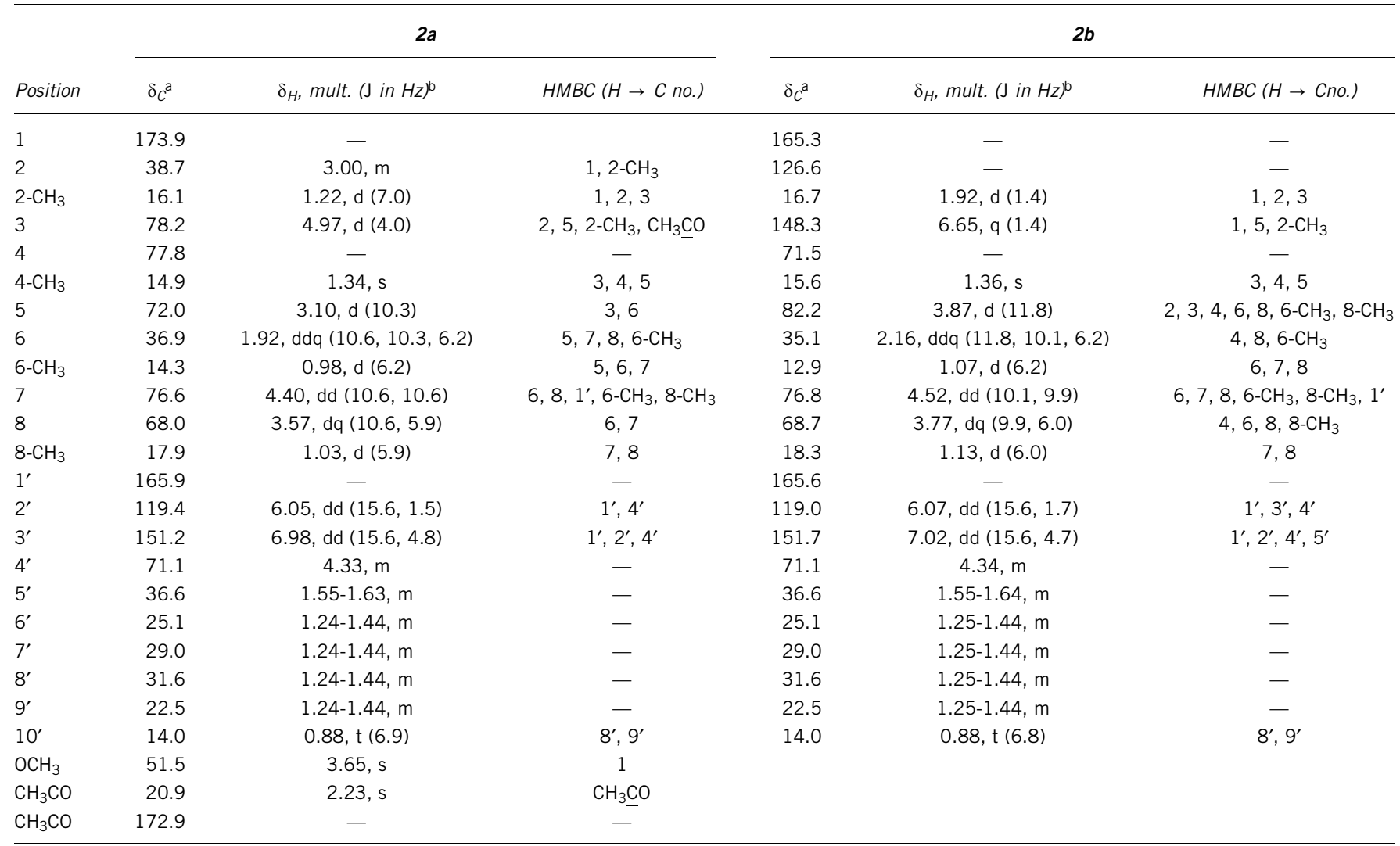

aRecorded at $100 \mathrm{MHz}$.

becorded at $400 \mathrm{MHz}$.

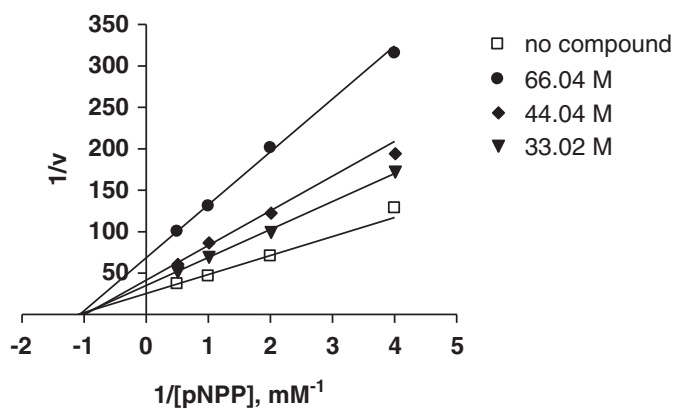

Figure 2 Kinetic analysis of PTP1B Inhibition by botcinin B (2) as Illustrated by a Lineweaver-Burk Plot. Data are expressed as mean initial velocity for $n=3$ replicates at each substrate concentration. Concentrations $(\mu \mathrm{M})$ of $\mathbf{2}$ are indicated in the figure.

implying that these compounds may bind to the enzyme-substrate complex or to an allosteric site within PTP1B. ${ }^{12,13}$

Botcinins are unusual bicyclic lactones containing a $\gamma$-hydroxy- $\alpha, \beta$ unsaturated carboxylic acid, unit with an aliphatic alkyl chain, and were originally isolated from Botrytis cinerea as antifungal agents. ${ }^{8,9,14}$ These compounds have been targets of asymmetric total synthesis, ${ }^{15,16}$ and the structure revision of boticinolides, previously reported as nine-membered lactones, to botcinin-type structures has been proposed. ${ }^{9}$ In the study described here, PTP1B inhibitory effects of botcinins and related compounds were identified for the first time, and the chemical instability of botcinins A and B in methanol solution was recognized, leading to the identification of two new botcinin derivatives.

\section{ACKNOWLEDGEMENTS}

This research was supported by grants from the Leading Foreign Research Institute Recruitment Program through the National Research Foundation of Korea (NRF) funded by the Ministry of Education, Science and Technology (No. M60602000001-06E0200-00100) and the Marine Biotechnology Program Funded by Ministry of Land, Transport and Maritime Affairs of Korean Government.

1 Fenical, W. \& Jensen, P. R. Developing a new resource for drug discovery: marine actinomycete bacteria. Nat. Chem. Biol. 2, 666-673 (2006).

2 Bugni, T. S. \& Ireland, C. M. Marine-derived fungi: a chemically and biologically diverse group of microorganisms. Nat. Prod. Rep. 21, 143-163 (2004).

3 Saleem, M. et al. Marine natural products of fungal origin. Nat. Prod. Rep. 24, 1142-1152 (2007).

4 Molinski, T. F., Dalisay, D. S., Lievens, S. L. \& Saludes, J. P. Drug development from marine natural products. Nat. Rev. Drug Discov. 8, 69-85 (2009).

5 Zhang, Y.- N. et al. Oleanolic acid and its derivatives: new inhibitor of protein tyrosine phosphatase 1B with cellular activities. Bioorg. Med. Chem. 16, 8697-8705 (2008).

6 Klaman, L. D. et al. Increased energy expenditure, decreased adiposity, and tissuespecific insulin sensitivity in protein-tyrosine phosphatase 1B-deficient mice. Mol. Cell. Biol. 20, 5479-5489 (2000).

7 Elchebly, M. et al. Increased insulin sensitivity and obesity resistance in mice lacking the protein tyrosine phosphatase 1B gene. Science 283, 1544-1548 (1999).

8 Tani, H., Koshino, H., Sakuno, E. \& Nakajima, H. Botcinins A, B, C, and D, metabolites produced by Botrytis cinerea, and their antifungal activity against Magnaporthe grisea, a pathogen of rice blast disease. J. Nat. Prod. 68, 1768-1772 (2005). 
9 Tani, H., Koshino, H., Sakuno, E., Cutler, H. G. \& Nakajima, H. Botcinins E and F and Botcinolide from Botrytis cinerea and structure revision of botcinolides. J. Nat. Prod. 69, 722-725 (2006).

10 Collado, I. G., Aleu, J., Hernandez-Galan, R. \& Hanson, J. R. Some metabolites of Botrytis cinerea related to botcinolide. Phytochemistry 42, 1621-1624 (1996).

11 Zhang, W. et al. Ursolic acid and its derivative inhibit protein tyrosine phosphatase 1B, enhancing insulin receptor phosphorylation and stimulating glucose uptake. Biochem. Biophy. Acta. 1760, 1505-1512 (2006).

12 Wiesmann, C. et al. Allosteric inhibition of protein tyrosine phosphatase 1B. Nat. Struct. Mol. Biol. 11, 730-737 (2004).
$13 \mathrm{Liu}$, S. et al. Targeting inactive enzyme conformation: aryl diketoacid derivatives as a new class of PTP1B inhibitors. J. Am. Chem. Soc. 130, 17075-17084 (2008).

14 Sakuno, E., Tani, H. \& Nakajima, H. 2-epi-Botcinin A and 3-0-acetylbotcineric acid from Botrytis cinerea. Biosci. Biotechnol. Biochem. 71, 2592-2595 (2007).

15 Fukui, H. \& Shiina, I. Asymmetric total synthesis of botcinins C, D, and F. Org. Lett. 10, 3153-3156 (2008).

16 Shiina, I. \& Fukui, H. Chemistry and structural determination of botcinolides, botcinins, and botcinic acids. Chem. Commun. 385-400 (2009).

Supplementary Information accompanies the paper on The Journal of Antibiotics website (http://www.nature.com/ja) 